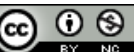

\title{
Uma análise de concursos públicos sob a perspectiva dos saberes docentes de Tardif
}

\author{
Rodrigo Herman Silva \\ Instituto Federal de Minas Gerais - IFMG, Bambuí, MG, Brasil \\ Marilene Ribeiro Resende \\ Universidade de Uberaba - UNIUBE, Uberaba, MG, Brasil \\ Vania Maria Oliveira Vieira \\ Universidade de Uberaba - UNIUBE, Uberaba, MG, Brasil
}

\section{RESUMO}

Com o objetivo de melhorar o processo de ensino e aprendizagem e de promover a educação integral do aluno, o campo da formação docente estuda o que o professor necessita saber para bem conduzir o seu trabalho. Por outro lado, as instituições de ensino públicas devem realizar concursos para selecionar os docentes que melhor atendam às suas necessidades. Nesse sentido, esta pesquisa analisou os editais de concursos para docentes efetivos do Ensino Básico Técnico e Tecnológico - EBTT, de cinco Institutos Federais de Educação, Ciência e Tecnologia do estado de Minas Gerais sob a perspectiva da caracterização dos saberes docentes de Maurice Tardif, a fim de identificar o que se espera desse professor a partir do que ele deve saber para ingressar na carreira. Observou-se que os editais dos concursos têm privilegiado os saberes disciplinares em detrimento dos saberes profissionais, curriculares e experienciais. Consequentemente, o perfil dos professores selecionados se aproxima mais da racionalidade técnica do que da formação integral proposta aos discentes no Ensino Médio Integrado ofertado por esses Institutos.

PALAVRAS-CHAVE: Ensino Médio Integrado. Formação Docente. Concurso Público.

\section{AN ANALYSIS OF PUBLIC EXAMINATIONS FROM THE PERSPECTIVE OF TEACHING KNOWLEDGE IN TARDIF}

\begin{abstract}
With the objective of improving the teaching and learning process and promoting the student's integral education, the field of teacher education studies what teachers need to know to carry out their work well. On the other hand, public education institutions must hold competitions to select the teachers who best meet their needs. In this sense, this research analyzed the public tenders for permanent teachers from five Federal Institutes of Education, Science and Technology in the state of Minas Gerais from the perspective of characterizing the teaching knowledge of Maurice Tardif, to identify what is expected of this teacher from what he must know to enter
\end{abstract}


the career. It was observed that the public notices of the competitions have privileged disciplinary knowledge to the detriment of professional, curricular, and experiential knowledge. Consequently, the profile of the selected teachers is closer to technical rationality than to the comprehensive training proposed to students in Integrated High School offered by these Institutes.

KEYWORDS: Integrated High School. Teacher Training. Public examination.

\section{UN ANÁLISIS DE LOS EXÁMENES PÚBLICOS DESDE LA PERSPECTIVA DE LA ENSEÑANZA DEL CONOCIMIENTO EN TARDIF}

\section{RESUMEN}

Con el objetivo de mejorar el proceso de enseñanza y aprendizaje y promover la educación integral del alumno, el campo de la formación docente estudia lo que los docentes necesitan saber para realizar bien su trabajo. Por otro lado, las instituciones de educación pública deben realizar concursos para seleccionar a los docentes que mejor se adapten a sus necesidades. En este sentido, esta investigación analizó las licitaciones públicas de docentes efectivos de cinco Institutos Federales de Educación, Ciencia y Tecnología del estado de Minas Gerais desde la perspectiva de caracterizar el conocimiento docente de Maurice Tardif, con el fin de identificar qué se espera de este maestro de lo que debe saber para ingresar a la carrera. Se observó que las convocatorias públicas de los concursos han privilegiado los conocimientos disciplinarios en detrimento de los conocimientos profesionales, curriculares y vivenciales. En consecuencia, el perfil de los docentes seleccionados se acerca más a la racionalidad técnica que a la formación integral propuesta a los estudiantes de Bachillerato Integrado que ofrecen estos Institutos.

PALABRAS-CLAVE: Enseñanza Media Integrada. Formación de profesores. Exámenes Públicos.

\section{INTRODUÇÃO}

Entre as lembranças agradáveis da maioria das pessoas adultas, geralmente estão um ou dois professores que marcaram a sua infância, não apenas por ensinar matemática ou química, mas também pelo carinho, cuidado, postura, sabedoria, comportamento ético e conhecimentos da vida em geral. São docentes que educam seus pequenos alunos de uma forma mais completa e humanizada, por saberem muito além do conteúdo específico da sua disciplina.

Nesse sentido, Gatti (2015, p.230) afirma que “o professor assumirá valor essencial quando se tornar um mestre - aquele que, além do saber indispensável a um professor, mostrase como uma lição de humanidade". O professor que se torna mestre é capaz de dar verdadeiras lições de vida a cada aula, mas, para que isso aconteça, a formação desse professor precisa ir além do conhecimento científico.

Ele precisa também de conhecimentos que abrangem as várias ciências ligadas à educação, de uma formação mais humanista, a qual harmoniza os conhecimentos com as relações humanas no contexto da escola e no contexto social mais amplo, e de experiência docente e de 
vida. Estudos sobre a formação docente têm apontado que o professor é um profissional diferenciado, que necessita de uma formação inicial adequada e depois, ao longo da sua vida profissional, de uma formação continuada muito bem planejada.

O campo de conhecimento em educação e, consequentemente, o da formação docente são complexos e multidisciplinares. Eles abrangem a Filosofia da Educação, a Didática, a Sociologia da Educação, as Políticas e Legislações Educacionais, a Psicologia Educacional, a História da Educação, a Gestão Escolar entre vários outros componentes que foram reunidos no termo Ciências da Educação. São muitos saberes em diferentes áreas, o que justifica o estudo mais aprofundado do processo de formação docente.

Em contraposição a essa visão sobre a formação docente como um campo do conhecimento, Siqueira (2017, p.70) aponta que, historicamente, no Brasil, "pessoas sem formação pedagógica podem atuar como docentes". A legislação brasileira sobre educação tem permitido, ao longo da história, que profissionais graduados em qualquer curso superior pudessem atuar como docentes, desde que eles tivessem os conhecimentos técnicos na área em que vão lecionar, sem levar em conta uma preparação própria para que esses profissionais possam atuar como docentes.

Mesmo que a legislação brasileira tenha tentado corrigir esse fato solicitando que tais professores, que já estejam atuando na educação básica, cursem uma licenciatura ou façam um curso de complementação pedagógica, o estrago já estava feito (BRASIL, 2008, 2019). A prática histórica desvalorizou a profissão docente e conduziu a sua formação para uma visão estritamente técnica.

Fiorentini e Crecci (2013, p.16) afirmam que, "no Brasil, o modelo majoritário de práticas indutoras ou catalisadoras de desenvolvimento profissional pode ser considerado ainda fortemente alinhado ao modelo da racionalidade técnica". Essa valorização da racionalidade técnica resulta num professor especialista, que reduz a sua atuação docente a um modelo utilitarista, que privilegia a transmissão de conhecimentos técnicos para formar mão de obra especializada para o mercado de trabalho, e que resolve os problemas em sala de aula a partir de um conjunto de ferramentas já conhecidas.

A visão utilitarista da educação, que visa atender somente aos interesses do mercado, priva a sociedade de uma educação mais ampla, que forma cidadãos com uma visão crítica do mundo, capazes de ter opinião própria, compreender e transformar o meio em que vivem e de exercer plenamente a sua cidadania.

A pobreza de recursos e de compreensão, de que esse professor especialista dispõe para a sua prática docente, é muito bem expressa por Pérez Gómez (1991, apud CONTRERAS 
DOMINGO, 2002, p. 99) ao afirmar que, "Na concepção da ciência que subjaz à epistemologia positivista, não existem esquemas, nem métodos, nem estratégias que permitam se aproximar da complexidade do componente artístico da atividade prática".

Se, por um lado, a educação brasileira tem sido prejudicada por uma visão reducionista e utilitarista, por outro ela tem sido beneficiada pelo processo de universalização da educação pública. O Brasil iniciou esse processo tardiamente em relação a países mais desenvolvidos, portanto necessita fazê-lo de forma acelerada, mas sem renunciar a um ensino público e de qualidade para todos.

A educação pública no país é ofertada pelos três níveis do governo: municipal, estadual e federal, segundo o artigo $8^{\circ}$ da Lei de Diretrizes Básicas da Educação - LDB (BRASIL, 1996). Segundo a Constituição Federal de 1988 (BRASIL, 1988), nesses três casos, a admissão de professores é feita por intermédio de concursos públicos de provas e títulos. Sobre os concursos públicos, Daher (2012, p.140) afirma que:

[...] para além das funções de avaliar, selecionar e classificar, os concursos públicos vinculam-se a uma memória discursiva, ou seja, constituem um patrimônio acerca do que 'se diz sobre', 'se espera' e 'se deve saber' para vir a ser professor da rede pública.

Nesse sentido, esta pesquisa se propõe a analisar os editais de concursos públicos para docentes efetivos dos Institutos Federais de Educação, Ciência e Tecnologia do estado de Minas Gerais de acordo com a tipologia de saberes de Maurice Tardif, com o objetivo de identificar o que se espera desse docente, a partir daquilo que ele deve saber para ingressar na profissão.

O uso da tipologia de saberes docentes se justifica pela pesquisa de Neto (2016), que aponta Tardif entre os autores mais citados e referenciados em trabalhos científicos do Instituto Brasileiro de Informação em Ciência e Tecnologia - IBICT, assegurando, assim, o reconhecimento de sua teoria no Brasil.

Por sua vez, a análise dos editais de concursos dos Institutos Federais de Educação, Ciência e Tecnologia se justifica pela concentração de cursos integrados de ensino médio nessas instituições. Historicamente, a educação profissional no Brasil tinha o objetivo de dar aos filhos da classe trabalhadora uma formação técnica que atendesse ao mercado de trabalho, enquanto aos filhos da elite era ofertada uma educação geral que lhes possibilitasse seguir com os estudos no ensino superior.

Os cursos de ensino médio integrado, como os que são ofertados pelos Institutos Federais (IF), surgiram como uma possibilidade de quebra dessa dicotomia da educação brasileira, pois, segundo o Documento Base do Ministério da Educação (BRASIL, 2007), a integração do 
ensino médio à educação profissional técnica cria um caminho para chegar a uma formação que supera a histórica separação entre a educação da elite e da classe trabalhadora.

Nesse sentido, a LDB (BRASIL, 1996) estabelece que, no ensino médio, o aluno possa ser preparado para o exercício de profissões técnicas, desde que seja atendida a formação geral do educando.

Para alcançar essa quebra de paradigma, espera-se que os concursos para docentes realizados pelos IF avaliem, selecionem e classifiquem profissionais que vão além da racionalidade técnica do professor especialista, que tem como finalidade principal fornecer mão de obra especializada para o mercado de trabalho.

Além desta introdução, o texto compreende quatro seções: na primeira, apresenta-se brevemente a tipologia dos saberes docentes elaborada por Maurice Tardif; na segunda, apresentam-se a metodologia da pesquisa e da análise dos editais; na terceira, os resultados da pesquisa são discutidos em relação a autores de outros estudos da área; e, por último são apresentadas as conclusões sobre o trabalho realizado.

\section{QUADRO TEÓRICO: OS SABERES DOCENTES SEGUNDO TARDIF}

O estudo da formação docente traz consigo uma grande questão: o que os professores precisam saber para bem conduzir o processo de ensino e aprendizagem? Vários pesquisadores têm estudado o tema e elaborado suas propostas ou modelos para responder a essa questão. Entre eles se destacam, no Brasil, as publicações do pesquisador canadense Maurice Tardif (NETO, 2016).

Tardif (2012) aponta que o problema do saber docente é a sua pluralidade e complexidade, como um saber social que ele é. Ele é social na sua prática, pois o professor trabalha com outros docentes numa mesma instituição partilhando o mesmo ambiente e condições.

É um saber social também quanto à sua formação, pois é um saber fazer que foi construído na interação com a sua família, com a escola em que ele se formou e com a sua experiência pessoal, seja na educação, ou em outras áreas de trabalho.

Tardif (2012) divide os saberes docentes em quatro categorias: profissionais, disciplinares, curriculares e experienciais. Os saberes profissionais são transmitidos pelas instituições de formação de professores e se dividem em saberes pedagógicos e em saberes das ciências da educação.

Os saberes disciplinares são oriundos dos diversos campos científicos (matemática, física, química, história etc.) e são oferecidos pelos departamentos universitários, mas não estão ligados aos saberes da educação ou profissionais. 
Os saberes curriculares correspondem aos saberes sociais definidos e selecionados pela escola, dentro do seu próprio modelo. São os programas escolares, objetivos, conteúdos e métodos que os professores devem aplicar dentro da instituição escolar em que trabalham.

Por último e talvez o mais elaborado, o saber experiencial é o conjunto de saberes que vêm da prática da profissão docente, que não provêm das instituições de formação, mas resultam delas. Eles têm caráter prático, emanam do exercício da profissão e, por virem da experiência, são constantemente atualizados e modificados.

O autor identifica as características do saber experiencial como um saber prático, interativo, sincrético e plural, heterogêneo, completo e não analítico, aberto e permeável, existencial e vivencial. Por fim, ele critica a racionalidade técnica, ao afirmar que os professores são sujeitos do seu conhecimento. Eles possuem saberes específicos ao seu ofício, e seu trabalho cotidiano não é somente a aplicação de saberes produzidos por outros, mas também, um espaço de produção, de transformação e de mobilização de saberes que lhes são próprios (TARDIF, 2012).

\section{METODOLOGIA}

Quanto à sua natureza, este estudo classifica-se como exploratório, pois pretende identificar o que se espera do docente, a partir daquilo que ele deve saber para ingressar na profissão através de concurso público. Segundo Gil (2002), as pesquisas exploratórias têm como propósito proporcionar maior familiaridade com o problema, com vistas a torná-lo mais explícito ou a construir hipóteses.

Também se trata de estudo descritivo, pois pretende descrever os saberes docentes exigidos para admissão nos Institutos Federais, usando como referência a tipologia de saberes de Tardif. Na concepção de Gil (2002), o estudo descritivo tem como papel principal descrever as características de uma determinada população ou fenômeno ou o estabelecimento de relações entre as variáveis.

Quanto ao delineamento, trata-se de uma pesquisa documental e bibliográfica, pois extrai dados de editais de concursos que, depois de agrupados, foram analisados à luz das contribuições de Tardif e de obras e artigos da área da educação. Finalmente pode ser definido como qualitativo, visto que, em princípio, não se utiliza de instrumental estatístico na análise dos dados, considera-se a participação não neutra do pesquisador (YIN, 2016).

Foram selecionados apenas editais que estavam disponíveis nos sites dos Institutos Federais de Educação, Ciência e Tecnologia do estado de Minas Gerais. Atualmente, em Minas Gerais existem cinco institutos, os quais se subdividem em diversos campus, e um edital de concurso pode atender a mais de uma dessas subdivisões (Quadro 1). 
Quadro 1 - Visão geral do acesso aos editais

\begin{tabular}{|c|c|c|}
\hline Instituição/Edital & Edital & Página eletrônica do edital (acesso em 10/07/2021) \\
\hline $\begin{array}{l}\text { IF Sul de Minas } \\
\text { (IFSM) }\end{array}$ & $\begin{array}{l}\text { Edital } \\
168 / 2018\end{array}$ & $\begin{array}{l}\text { https://concurso.ifsuldeminas.edu.br/index.php? } \\
\text { option=com_content\&view=article\&id=297:edital-1 } \\
\text { 682018-docente-efetivo-campus-pouso-alegre\&catid } \\
=43: \text { encerrados\&Itemid=56 }\end{array}$ \\
\hline $\begin{array}{l}\text { IF Triângulo Mi- } \\
\text { neiro (IFTM) }\end{array}$ & $\begin{array}{l}\text { Edital } \\
055 / 2015\end{array}$ & $\begin{array}{l}\text { https://iftm.edu.br/concursos/processo/? } \\
\text { id=Ccsy_IjMSCRJ96ZqN }\end{array}$ \\
\hline $\begin{array}{l}\text { IF Norte de Minas } \\
\text { Gerais (IFNMG) }\end{array}$ & $\begin{array}{l}\text { Edital } \\
322 / 2018\end{array}$ & $\begin{array}{l}\text { https://www.ifnmg.edu.br/professor-efetivo/19470- } \\
\text { professor-efetivo-edital-n-322-2018 }\end{array}$ \\
\hline $\begin{array}{l}\text { IF Minas Gerais } \\
\text { (IFMG) }\end{array}$ & $\begin{array}{l}\text { Edital } \\
86 / 2018+ \\
82 / 2018 \\
\text { (regras } \\
\text { gerais) }\end{array}$ & $\begin{array}{l}\text { https://www.in.gov.br/materia/-/asset_publisher/Kujrw0TZC2Mb/ } \\
\text { content/id/51554502/do3-2018-11-23-edital-n-82-2018 } \\
\text { concurso-publico-de-provas-e-titulos-para-o- } \\
\text { provimento-dos-cargos-da-carreira-do-magisterio-do-ensino-basico- } \\
\text { tecnico-e-tecnologico-51553941 }\end{array}$ \\
\hline $\begin{array}{l}\text { IF Sudeste de Mi- } \\
\text { nas Gerais } \\
\text { (IFSMG) }\end{array}$ & $\begin{array}{l}\text { Edital } \\
03 / 2018\end{array}$ & $\begin{array}{l}\text { https://concurso.fundacaocefetminas.org.br/site/processo se- } \\
\text { letivo } \\
\text { detalhes.aspx?id=0DC681BB6C16403D }\end{array}$ \\
\hline
\end{tabular}

Fonte: Elaborado pelo autor (2021)

Observou-se que os editais para admissão de docentes efetivos envolvem maior número de vagas e por isso ocorrem esporadicamente, geralmente em intervalos de um ano ou mais. Devido a essa baixa frequência de concursos, foi selecionado apenas um edital por instituição, totalizando cinco editais. Essa amostragem permitiu uma análise mais ampla e a identificação de padrões de comportamento numa mesma região. Registra-se que esses editais são documentos públicos, disponíveis eletronicamente, e a informação neles contida é de livre acesso.

Foram selecionados editais de concurso para docentes efetivos, independentemente da área ou disciplina, sendo excluídos os editais simplificados para docentes substitutos, para docentes temporários e para outras funções técnicas. Foram selecionados apenas editais anteriores às condições diferenciadas adotadas durante a pandemia de Covid-19, ou seja, foram excluídos os editais elaborados no contexto da emergência sanitária.

Com relação ao período, considerou-se o último Edital para professor efetivo, listado no site de cada uma das instituições. Assim, foram selecionados quatro editais do ano de 2018 e apenas um do ano de 2015. Não se identificou concurso para efetivos em 2019; e, em 2020, quando houve o início da pandemia, o que levou à interrupção de atividades presenciais nas instituições de ensino.

Todos os editais foram completamente lidos e as informações foram agrupadas pelos saberes docentes para melhor compreensão. No Quadro 2, segue uma visão geral dos cinco concursos analisados nesta pesquisa, registrando, inclusive, as fórmulas de cálculo do resultado final e a nota máxima possível de cada concurso. 
Quadro 2 - Visão geral dos concursos analisados

\begin{tabular}{|l|l|c|}
\hline \multicolumn{1}{|c|}{$\begin{array}{c}\text { Instituição/ } \\
\text { Edital }\end{array}$} & \multicolumn{1}{|c|}{ Cálculo do Resultado Final } & $\begin{array}{c}\text { Nota Máxima } \\
\text { Possível }\end{array}$ \\
\hline $\begin{array}{l}\text { IFSM - edital } \\
168 / 2018\end{array}$ & $\begin{array}{l}\text { A nota final dos candidatos foi obtida através da seguinte fór- } \\
\text { mula: TP = (PE*2) + (PDD*3) + PT } \\
\text { Prova escrita (peso dois), prova de desempenho didático (peso } \\
\text { três) e prova de títulos (peso um) }\end{array}$ & 500 pontos \\
\hline $\begin{array}{l}\text { IFTM - edital } \\
\text { 055/2015 }\end{array}$ & $\begin{array}{l}\text { A nota final dos candidatos foi obtida pela soma da pontuação } \\
\text { obtida nas provas objetiva, desempenho didático-pedagógico e } \\
\text { prova de títulos }\end{array}$ & 250 pontos \\
\hline $\begin{array}{l}\text { IFNMG - edi- } \\
\text { tal 322/2018 }\end{array}$ & $\begin{array}{l}\text { A nota final dos candidatos foi obtida pela soma da pontuação } \\
\text { obtida nas provas objetiva de múltipla escolha, dissertativa, de } \\
\text { desempenho didático e prova de títulos }\end{array}$ & 400 pontos \\
\hline $\begin{array}{l}\text { IFMG }- \text { edital } \\
86 / 2018+ \\
82 / 2018 \text { (re- } \\
\text { gras gerais) }\end{array}$ & $\begin{array}{l}\text { A nota final dos candidatos foi obtida pela soma das notas obti- } \\
\text { das nas fases 2, 3 e 4, atribuídos os pesos conforme segue: Nota } \\
\text { final = [Nota Prova Dissertativa x 0,3] + [Nota de Desempenho } \\
\text { Didático x 0,4] + [Nota Títulos x 0,3] }\end{array}$ & 100 pontos \\
\hline $\begin{array}{l}\text { IFSMG - edi- } \\
\text { tal 03/2018 }\end{array}$ & $\begin{array}{l}\text { A nota final dos candidatos foi obtida pela soma da pontuação } \\
\text { obtida nas provas objetiva de múltipla escolha; dissertativa; de } \\
\text { desempenho didático e prova de títulos }\end{array}$ & 100 pontos \\
\hline
\end{tabular}

Fonte: Elaborado pelo autor (2021)

Observa-se que os concursos têm a mesma estrutura, isto é, três etapas, prova escrita, prova de desempenho didático e a de títulos, variando os pesos atribuídos a cada uma delas. As provas e bibliografias do concurso foram agrupadas e relacionadas com cada um dos saberes docentes estabelecidos por Tardif, criando, assim, uma escala que permitiu avaliar quais tipos de saberes foram mais exigidos para o ingresso na instituição de ensino e quais tipos de saberes foram negligenciados ou não foram sequer considerados nas provas (NETO, 2016).

Nesse sentido, foram classificados como saberes disciplinares: os conhecimentos específicos da área do concurso, os conhecimentos da língua portuguesa e os conhecimentos sobre a legislação do ensino público, que compõem a prova escrita, o domínio do conteúdo específico, também avaliado na prova de desempenho didático, os títulos de doutorado, mestrado, e pósgraduação lato sensu, as produções científicas, técnicas e culturais, seja em forma de artigos, capítulos de livro, registro de patentes e participação em eventos científicos.

Foram classificados como saberes profissionais ou pedagógicos: os conhecimentos relativos à área de didática são avaliados em questões da prova escrita, em itens da prova de desempenho didático e na pontuação da prova de títulos no quesito "licenciatura".

Foram classificados como saberes experienciais a experiência profissional ou docente contabilizada em anos ou semestres de exercício profissional e as orientações acadêmicas diversas, avaliadas na prova de títulos. 
Seriam classificados como saberes curriculares os conhecimentos específicos sobre: o Plano de Desenvolvimento Institucional, os projetos pedagógicos dos cursos. Entretanto, não foram identificados tais saberes nos editais selecionados.

Após relacionar as provas e bibliografias previstas no concurso com cada um dos saberes docentes estabelecidos por Tardif, os resultados foram agrupados e apresentados pelas etapas previstas nos editais. Para cada etapa prevista, os pontos possíveis foram categorizados pelos saberes docentes e apresentados em números absolutos na forma de quadros.

Ao final da análise, os resultados foram agrupados por edital de concurso, a pontuação possível de cada edital foi subdividida pelos saberes docentes e apresentados em números relativos à nota máxima possível de cada edital na forma de gráfico.

\section{RESULTADOS E DISCUSSÃO}

As informações coletadas nos editais foram agrupadas pelas etapas dos concursos e os pontos possíveis em cada etapa foram subdivididos de acordo com a tipologia de saberes de Tardif, observando-se os pesos atribuídos aos diferentes instrumentos de avaliação. Atendendo à Constituição Federal (BRASIL, 1988), todos os editais analisados são classificados como concursos públicos de provas e títulos.

Quadro 3 - Análise da primeira etapa dos concursos - Prova escrita

\begin{tabular}{|c|c|c|c|}
\hline Instituição & Primeira Etapa & Saberes & $\begin{array}{c}\text { Pontos } \\
\text { possíveis }\end{array}$ \\
\hline IFSM & $\begin{array}{l}\text { Prova dividida em parte objetiva com questões sobre le- } \\
\text { gislação e parte discursiva abordando conhecimentos do } \\
\text { conteúdo específico. }\end{array}$ & $\begin{array}{l}\text { Profissionais } \\
\text { Disciplinares } \\
\text { Curriculares } \\
\text { Experienciais } \\
\text { Total da etapa }\end{array}$ & $\begin{array}{c}0 \\
200^{1} \\
0 \\
0 \\
200^{1}\end{array}$ \\
\hline IFTM & $\begin{array}{l}\text { Prova objetiva com questões de língua portuguesa, de } \\
\text { legislação e de conhecimentos específicos da área. }\end{array}$ & $\begin{array}{l}\text { Profissionais } \\
\text { Disciplinares } \\
\text { Curriculares } \\
\text { Experienciais } \\
\text { Total da etapa }\end{array}$ & $\begin{array}{c}0 \\
100 \\
0 \\
0 \\
100 \\
\end{array}$ \\
\hline IFNMG & $\begin{array}{l}\text { Prova dividida em parte objetiva com questões de didá- } \\
\text { tica, de legislação e de conhecimentos específicos da } \\
\text { área e parte discursiva também abordando também co- } \\
\text { nhecimentos específicos da área }\end{array}$ & $\begin{array}{l}\text { Profissionais } \\
\text { Disciplinares } \\
\text { Curriculares } \\
\text { Experienciais } \\
\text { Total da etapa }\end{array}$ & $\begin{array}{c}20 \\
180 \\
0 \\
0 \\
200 \\
\end{array}$ \\
\hline IFMG & $\begin{array}{l}\text { Prova dividida em parte objetiva com questões de co- } \\
\text { nhecimentos específicos da área, que não entra no cál- } \\
\text { culo do resultado final, e parte discursiva também abor- } \\
\text { dando apenas conhecimentos específicos da área }\end{array}$ & $\begin{array}{l}\text { Profissionais } \\
\text { Disciplinares } \\
\text { Curriculares } \\
\text { Experienciais } \\
\text { Total da etapa }\end{array}$ & $\begin{array}{c}0 \\
30^{1} \\
0 \\
0 \\
30^{1} \\
\end{array}$ \\
\hline
\end{tabular}




\begin{tabular}{|l|l|l|c|}
\hline IFSMG & Prova dividida em parte objetiva com questões de co- & Profissionais & 0 \\
& nhecimentos específicos da área e parte discursiva tam- & Disciplinares & 50 \\
& bém abordando conhecimentos específicos da área & Curriculares & 0 \\
& & Experienciais & 0 \\
& & Total da etapa & 50 \\
\hline
\end{tabular}

Fonte: Elaborado pelo autor (2021)

Nota1: Considerando os pesos

Em termos de formato, a primeira etapa de todos os concursos analisados aborda apenas aspectos teóricos com questões de múltipla escola ou combinações desse tipo com questões dissertativas sobre temas sorteados. Mendes e Horn (2011) apontam a superioridade em concursos públicos das provas dissertativas com relação às provas de múltipla escolha. A combinação desses dois tipos de prova parece ser uma boa prática.

Em termos de conteúdo, a primeira etapa de todos os concursos analisados aborda apenas conhecimentos específicos da área combinados ou não com conhecimentos da língua portuguesa e de legislação do funcionalismo público, com exceção do edital 322/2018 do IFNMG, que aborda dez questões de didática, valendo vinte pontos (QUADRO 3).

Os saberes curriculares e experenciais identificados como essenciais à prática docente por Tardif não são abordados nesta etapa dos concursos e os saberes da formação profissional, na qual Tardif inclui os saberes pedagógicos, também são pouco avaliados. Considerando que o autor (2012, p.31) define o saber docente como "um saber plural, formado pelo amálgama mais ou menos coerente, de saberes oriundos da formação profissional e de saberes disciplinares, curriculares e das suas próprias experiências", o concurso que não aborda todos os saberes docentes pode ter o seu conteúdo empobrecido.

Quadro 4 - Análise da segunda etapa dos concursos - Prova de Desempenho Didático

\begin{tabular}{|c|c|c|c|}
\hline Instituição & Segunda Etapa & Saberes & $\begin{array}{c}\text { Pontos } \\
\text { possíveis }\end{array}$ \\
\hline IFSM & $\begin{array}{l}\text { Uma aula de trinta a quarenta minutos perante banca } \\
\text { examinadora com possibilidade de arguição de vinte mi- } \\
\text { nutos ao candidato referente ao tema sorteado. O ba- } \\
\text { rema é composto de Plano de aula/ Introdução Conte- } \\
\text { údo/ Procedimento/ Recursos/ Finalização/ Avaliação }\end{array}$ & $\begin{array}{l}\text { Profissionais } \\
\text { Disciplinares } \\
\text { Curriculares } \\
\text { Experienciais } \\
\text { Total da etapa }\end{array}$ & $\begin{array}{c}140^{1} \\
60^{1} \\
0 \\
0 \\
200^{1}\end{array}$ \\
\hline IFTM & $\begin{array}{l}\text { Uma aula de quarenta minutos perante banca examina- } \\
\text { dora com possibilidade de arguição de cinco minutos ao } \\
\text { candidato referente ao tema sorteado. O barema é com- } \\
\text { posto de Plano de aula/ Introdução/ Desenvolvimento/ } \\
\text { Metodologia/ Recurso didáticos/Comunicação/ Avalia- } \\
\text { ção }\end{array}$ & $\begin{array}{l}\text { Profissionais } \\
\text { Disciplinares } \\
\text { Curriculares } \\
\text { Experienciais } \\
\text { Total da etapa }\end{array}$ & $\begin{array}{c}35 \\
65 \\
0 \\
0 \\
100\end{array}$ \\
\hline IFNMG & $\begin{array}{l}\text { Uma aula de cinquenta minutos, ministrada perante } \\
\text { Banca Examinadora referente ao tema sorteado. O ba- } \\
\text { rema é composto de Plano de aula/ Atitudes e habilida- } \\
\text { des/ Introdução/ Desenvolvimento/ Finalização }\end{array}$ & $\begin{array}{l}\text { Profissionais } \\
\text { Disciplinares } \\
\text { Curriculares } \\
\text { Experienciais } \\
\text { Total da etapa }\end{array}$ & $\begin{array}{c}35 \\
65 \\
0 \\
0 \\
100\end{array}$ \\
\hline
\end{tabular}




\begin{tabular}{|c|l|l|c|}
\hline IFMG & $\begin{array}{l}\text { Uma aula de quarenta a cinquenta minutos perante } \\
\text { Banca Examinadora referente ao tema sorteado. O ba- } \\
\text { rema é composto de Plano de aula/Introdução/Desen- } \\
\text { volvimento/Finalização/Conduta. }\end{array}$ & $\begin{array}{l}\text { Profisionais } \\
\text { Disciplinares } \\
\text { Curriculares } \\
\text { Experienciais } \\
\text { Total da etapa }\end{array}$ & $\begin{array}{c}36^{1} \\
4^{1}\end{array}$ \\
0 \\
\hline \multirow{2}{*}{ IFSMG } & $\begin{array}{l}\text { Uma aula de quarenta a cinquenta minutos perante uma } \\
\text { banca examinadora referente ao tema sorteado. O ba- }\end{array}$ & $\begin{array}{l}\text { Profissionais } \\
\text { Disciplinares }\end{array}$ & 23 \\
& $\begin{array}{l}\text { rema é composto de Plano de aula/Objetivos precisos e } \\
\text { claros/Domínio do conteúdo/Adequação do conte- }\end{array}$ & 7 \\
& $\begin{array}{l}\text { Curriculares } \\
\text { Experienciais } \\
\text { údo/Distribuição cronológica/Recursos didáticos utili- } \\
\text { zados/Sequência lógica de raciocínio/Comunicação. }\end{array}$ & 0 \\
Total etapa & 30 \\
\hline
\end{tabular}

Fonte: Elaborado pelo autor (2021)

Nota1: Considerando os pesos e o barema, anexo aos editais.

Em termos de formato, a segunda etapa de todos os concursos analisados refere-se a uma prova de desempenho didático ou didático-pedagógico com uma aula perante banca examinadora com contagem de tempo, tema sorteado, avaliação por barema e arguição pela banca.

Por se tratar de uma pesquisa documental, a fase de desenvolvimento da aula e da arguição da prova de desempenho didático não se enquadra no escopo deste trabalho, quando outros saberes poderão ser observados, quer pelo apresentado pelo candidato, quer pelas arguições, que possam ser feitas. Registra-se, ainda, que nenhum edital previu fase de entrevistas aos candidatos, na qual se poderia avaliar outros saberes.

Em termos de conteúdo, os critérios de avaliação expressos nos baremas de cada concurso envolvem os saberes profissionais ao abordarem os aspectos técnicos e instrumentais da organização de uma aula como plano de aula, uso de recursos e uso do tempo, bem como os saberes disciplinares por meio de perguntas sobre o domínio do conteúdo específico (Quadro 4).

Ressalta-se que, em nenhum dos baremas, é solicitado que o candidato demonstre conhecimento sobre as teorias de aprendizagem e a sua aplicação em sala de aula. Franco (2008 p.133) afirma que, "o saber pedagógico é uma prática que exige do professor a consciência e a intencionalidade de buscar uma transformação do aluno, pois implica do exercício de uma prática reflexiva, comprometida, com sentido, com intencionalidade”. Entende-se, assim, que a prática pedagógica não se resume apenas à aplicação de técnicas e instrumentos e, como tal, não deve ser avaliada apenas por esse ponto de vista.

Os saberes curriculares e experenciais também não foram abordados nesta etapa do concurso. 
Quadro 5 - Análise da terceira etapa dos concursos - Prova de Títulos

\begin{tabular}{|c|c|c|c|}
\hline Instituição & Terceira Etapa & Saberes & $\begin{array}{c}\text { Pontos } \\
\text { possíveis }\end{array}$ \\
\hline IFSM & $\begin{array}{l}\text { Prova de títulos com pontuação para cursos de douto- } \\
\text { rado, mestrado, pós-graduaçâo lato sensu podendo so- } \\
\text { mar no máximo cinquenta pontos. A licenciatura foi } \\
\text { avaliada como vinte pontos. A experiência docente é } \\
\text { avaliada com um ponto por semestre até o máximo de } \\
\text { trinta pontos. }\end{array}$ & $\begin{array}{l}\text { Profissionais } \\
\text { Disciplinares } \\
\text { Curriculares } \\
\text { Experienciais } \\
\text { Total da etapa }\end{array}$ & $\begin{array}{c}20^{1} \\
50^{1} \\
0 \\
30 \\
200^{1}\end{array}$ \\
\hline IFTM & $\begin{array}{l}\text { Prova de títulos com pontuação para cursos de douto- } \\
\text { rado, mestrado, pós-graduação lato sensu e publicações } \\
\text { em periódicos ou livros no máximo vinte e sete pontos. } \\
\text { Orientações acadêmicas diversas podendo somar oitos } \\
\text { pontos. A experiência docente é avaliada com } 3 \text { pontos } \\
\text { por ano completo até o máximo de quinze pontos. }\end{array}$ & $\begin{array}{l}\text { Profissionais } \\
\text { Disciplinares } \\
\text { Curriculares } \\
\text { Experienciais } \\
\text { Total da etapa }\end{array}$ & $\begin{array}{c}0 \\
27 \\
0 \\
23 \\
50\end{array}$ \\
\hline IFNMG & $\begin{array}{l}\text { Prova de títulos com pontuação para títulos acadêmicos } \\
\text { e produção científica, técnica e cultural podendo somar } \\
\text { no máximo cinquenta e cinco pontos. Atividades docen- } \\
\text { tes como orientações e a experiência docente (avaliada } \\
\text { com } 2 \text { pontos por semestre até o máximo de vinte pon- } \\
\text { tos) podendo somar até quarenta e cinco pontos. }\end{array}$ & $\begin{array}{l}\text { Profissionais } \\
\text { Disciplinares } \\
\text { Curriculares } \\
\text { Experienciais } \\
\text { Total da etapa }\end{array}$ & $\begin{array}{c}0 \\
55 \\
0 \\
45 \\
100\end{array}$ \\
\hline IFMG & $\begin{array}{l}\text { Prova de títulos com pontuação para títulos acadêmicos } \\
\text { e produção científica, técnica e cultural podendo somar } \\
\text { no máximo } 19,5 \text { pontos. } \\
\text { Atividades docentes como orientações e a experiência } \\
\text { docente (avaliada com } 0,5 \text { ponto por semestre até o má- } \\
\text { ximo de nove pontos) podendo somar até trinta e cinco } \\
\text { pontos. }\end{array}$ & $\begin{array}{l}\text { Profissionais } \\
\text { Disciplinares } \\
\text { Curriculares } \\
\text { Experienciais } \\
\text { Total da etapa }\end{array}$ & $\begin{array}{c}0 \\
19,5^{1} \\
0 \\
10,5^{1} \\
30^{1}\end{array}$ \\
\hline IFSMG & $\begin{array}{l}\text { Prova de títulos com pontuação para cursos de douto- } \\
\text { rado, mestrado, pós-graduação lato sensu, produções } \\
\text { acadêmicas e científicas podendo somar no máximo } \\
\text { quatorze pontos. Licenciatura avaliada como três pon- } \\
\text { tos. A experiência docente é avaliada com } 0,1 \text { ponto por } \\
\text { semestre até o máximo de três pontos. }\end{array}$ & $\begin{array}{l}\text { Profissionais } \\
\text { Disciplinares } \\
\text { Curriculares } \\
\text { Experienciais } \\
\text { Total da etapa }\end{array}$ & $\begin{array}{c}0 \\
30 \\
0 \\
0 \\
30\end{array}$ \\
\hline
\end{tabular}

Fonte: Elaborado pelo autor (2021)

Nota1: Considerando os pesos

Em termos de formato, a terceira etapa de todos os concursos analisados trata-se de uma prova de títulos. Em termos de conteúdo, nessa etapa são atribuídas diferentes pontuações para as pós-graduações, as atividades e produções científicas, acadêmicas e tecnológicas e a experiência profissional. Chama a atenção a baixa pontuação atribuída à experiência docente que vai de 0,1 ponto por semestre, no caso do IFSMG, até 2 pontos por semestre, no caso do IFNMG (QUADRO 5). 
Gráfico 1 - Participação dos saberes docentes no resultado final de cada concurso

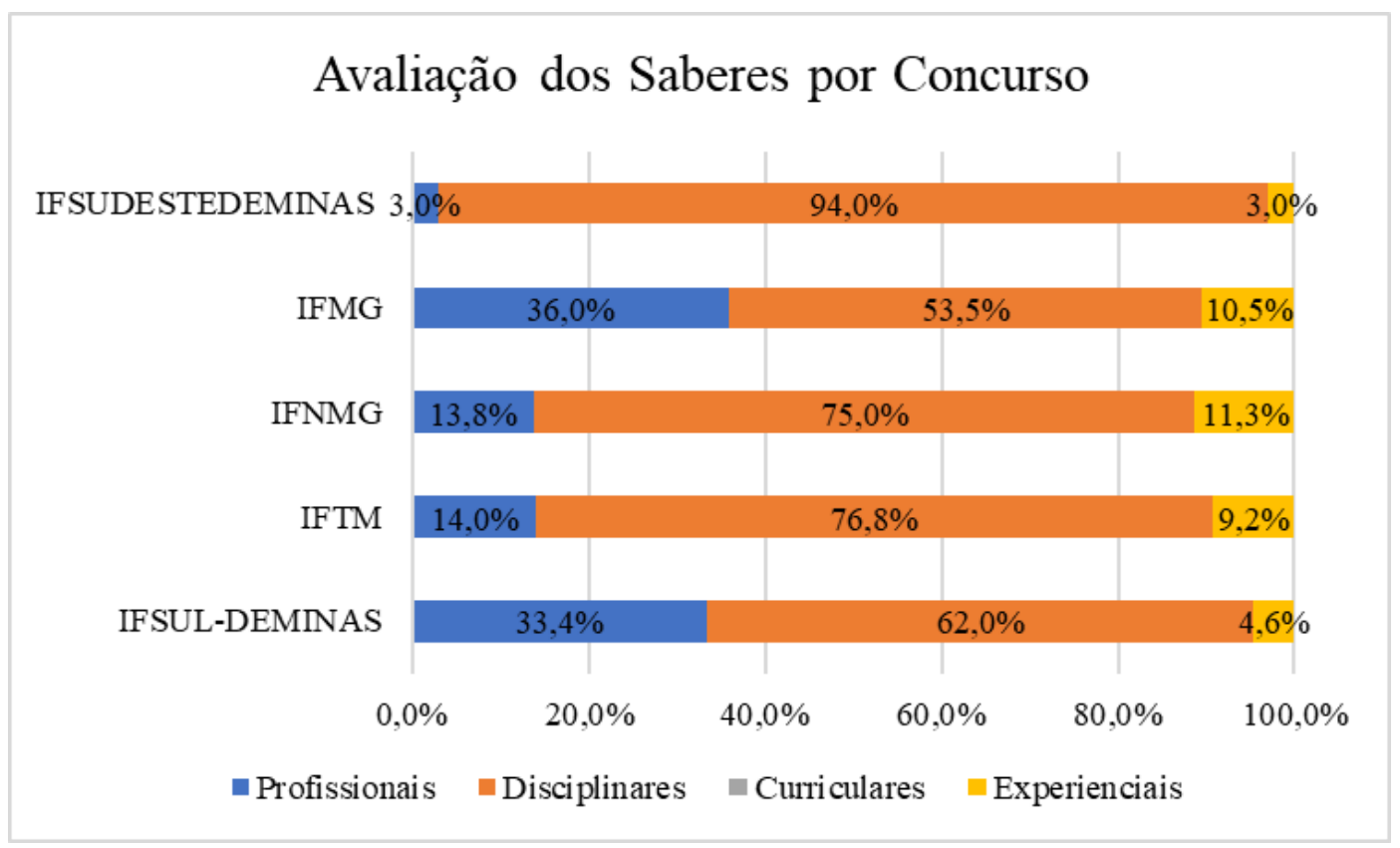

Fonte: Elaborado pelo autor (2021)

Conforme o Gráfico 1, todos os concursos analisados privilegiam os saberes disciplinares com uma participação no resultado final que vai de 94,0\%, no caso do IFSM, até 53,5\%, no caso do IFMG. Isso ocorre em detrimento dos saberes profissionais que têm uma participação de 3,0\%, no caso do IFSM, até 36\%, no caso do IFMG, e dos saberes experenciais, que têm uma participação de 3,0\%, no caso do IFSM, até 11,3\%, no caso do IFNMG.

Com relação aos saberes experienciais, Nikel (2019) analisou editais de concursos públicos contemplando a disciplina EDUCAÇÃO MUSICAL nas redes municipais de ensino básico e encontrou como resultado que a pontuação sobre experiência/prática representou apenas $1 \%$ da pontuação média dos editais analisados.

Ressalta-se que não foram encontradas em nenhum concurso analisado, avaliações referentes aos saberes curriculares, os quais são definidos e selecionados pela própria instituição escolar (TARDIF, 2012). Assim sendo, a sua ausência parece indicar que a escola não valoriza as suas características próprias, seus programas escolares, sua identidade, na seleção de seus docentes.

Num sentido mais amplo, Daher (2012) aponta que, ao se realizar um concurso público, aparentemente a instituição está mais preocupada em atender aos requisitos legais do edital do que selecionar e admitir um professor com o perfil adequado às necessidades da docência e da própria instituição. Aparentemente, o foco do concurso se desvia da sua função primordial, ao privilegiar o instrumento de seleção em detrimento da seleção de um docente com um perfil profissional mais adequado à instituição. 


\section{CONCLUSÃO}

Os resultados encontrados pela presente pesquisa, que não esgota o tema e tem limites, porque ficou restrita ao prescrito nos Editais, indicam que, de acordo com a tipologia de saberes docentes de Maurice Tardif, os Institutos Federais do estado de Minas Gerais têm privilegiado em seus concursos para docentes efetivos, em seus editais, os saberes disciplinares em detrimento dos saberes profissionais, curriculares e experienciais.

Essa valorização dos saberes disciplinares sugere que os professores admitidos nesses concursos têm um perfil mais próximo da racionalidade técnica ou positivista, o que, a princípio, não atenderia à proposta de formação integral do ensino médio integrado à educação profissional técnica.

A partir disso, sugere-se aprofundar nesses estudos de forma a tentar adequar os saberes exigidos nos concursos públicos com o perfil de professor que se deseja contratar e, ao mesmo tempo, planejar uma formação docente continuada de forma a suprir as lacunas que, porventura, sejam encontradas no perfil dos professores já contratados de forma a atender às necessidades dos cursos e consequentemente dos docentes em formação.

Espera-se ainda que a metodologia de análise dos editais sob a perspectiva dos saberes docentes, aplicada nesta pesquisa, possa inspirar mudanças nos próximos concursos de seleção para professores no ensino médio integrado, podendo gerar inclusive um documento de orientação para a elaboração de editais de concursos dentro dos Institutos Federais.

\section{REFERÊNCIAS}

BRASIL. Constituição (1988). Constituição da República Federativa do Brasil de 1998. Disponível em http://www.planalto.gov.br/ccivil_03/constituicao/constituicao.htm. Acesso em: 22 de jul. 2021

. Lei de Diretrizes e bases da Educação, no 9394, de 20 de dezembro de 1996. Disponível em: http://www.planalto.gov.br/ccivil_03/leis/19394.htm. Acesso em: 22 de jul. 2021

Ministério da Educação. Documento Base: educação profissional técnica de nível médio integrada ao ensino médio. Brasília, 2007. Disponível em: http://portal.mec.gov.br/setec/arquivos/pdf/documento_base.pdf. Acesso em: 22 de jul. 2021

Lei $n^{\circ} .11 .892$, de 29 de dezembro de 2008. Institui a Rede Federal de Educação Profissional, Científica e Tecnológica, cria os Institutos Federais de Educação, Ciência e Tecnologia, e dá outras providências. Disponível em: http://www.planalto.gov.br/ccivil_03/_ato20072010/2008/lei/l11892.htm . Acesso em: 22 de jul. 2021

CNE/MEC. Resolução $N^{o} 2$ CNE/CP de 20 de dezembro de 2019. Define as Diretrizes Curriculares Nacionais para a Formação Inicial de Professores para a Educação Básica e 
institui a Base Nacional Comum para a formação inicial de professores para a Educação Básica. Disponível em: http://portal.mec.gov.br/index.php?option=com_docman\&view=down-

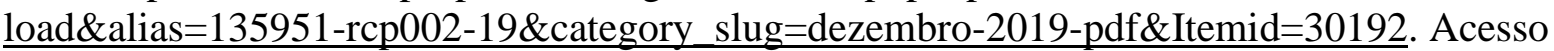
em: 22 de jul. 2021

CONTRERAS DOMINGO, José. A autonomia ilusória: o professor como profissional técnico. In: . A autonomia de professores. São Paulo: Cortez, 2002. p. 89-104. (Cap. 4)

NETO, Viana Patrício Barbosa; COSTA, Maria da Conceição. Saberes docentes: entre concepções e categorizações. Tópicos Educacionais (UFPE). Recife/PE, n. 2, p. 76-99, 2016.

DAHER, Del Carmen. Discurso e atividade de seleção de professores. Revista Moara, n. 38, p. 140-158, jul.-dez., 2012.

FIORENTINI, Dario; CRECCI, Vanessa. Desenvolvimento profissional docente: um termo guarda-chuva ou um novo sentido à formação? Formação Docente - Revista Brasileira de Pesquisa sobre Formação de Professores, v. 5, n. 8, p. 11-23, 30 jun. 2013.

FRANCO, Maria Amélia do Rosário Santoro. Pedagogia como ciência da educação. 2.ed. São Paulo: Cortez, 2008.

GATTI, Bernadete Angelina. Formação de professores: compreender e revolucionar. In: SILVA JÚNIOR, Celestino Alves da et al. Por uma revolução no campo da formação de professores. São Paulo: Editora Unesp, 2015. 229-243.

GIL, Antonio Carlos et al. Como elaborar projetos de pesquisa. São Paulo: Atlas, 2002.

MENDES, Ademir Aparecido Pinhelli; HORN, Geraldo Balduíno. O ensino de filosofia e a seleção de professores para o ensino médio das escolas públicas paranaenses. Educação em Revista, v. 12, n. 1, p. 109-124, 2011.

NIKEL, Mateus Alencar. Prática docente em concursos para o magistério: a desvalorização dos saberes da experiência. Dissertação (Mestrado em Educação) - Universidade Federal do Rio de Janeiro, 2019. $143 \mathrm{f}$.

SIQUEIRA, A. P. M. Formação continuada e desenvolvimento profissional docente: representações de professores. Dissertação (Mestrado), Pontifícia Universidade Católica do Paraná, Curitiba, 2017, p $62-72$.

TARDIF, Maurice. Saberes docentes e formação profissional. Editora Vozes Limitada, 2012.

YIN, Robert K. Pesquisa qualitativa do início ao fim. Penso Editora, 2016.

\section{SOBRE OS AUTORES}

Rodrigo Herman Silva possui graduação em Engenharia Industrial Mecânica pelo Centro Federal de Educação Tecnológica de Minas Gerais (1996). Cursos de aperfeiçoamento nas áreas de Gestão Tecnológica (1998) e Gestão Ambiental (2005). Especialização em Gestão da Qualidade (2001) e Mestrado em Desenvolvimento Regional (2016). Atuou como engenheiro por 11 anos em empresas das áreas de Metal-Mecânica, Biotecnologia e Siderurgia. Atualmente é professor de Ensino Básico, Técnico e 
Tecnológico e coordenador de curso no Instituto Federal Minas Gerais - Campus Bambuí. Aluno do curso de doutorado do Programa de Pós-graduação em Educação da Uniube.

E-mail: rodrigo.herman@ifmg.edu.br

ORCID: https://orcid.org/0000-0003-4936-5994

Marilene Ribeiro Resende possui Licenciatura em Matemática - Faculdades Integradas Santo Tomas de Aquino (1973), mestrado em Educação Matemática pela Universidade Estadual Paulista Júlio de Mesquita Filho (1991) e doutorado em Educação Matemática pela Pontifícia Universidade Católica de São Paulo (2007). Atualmente é professora titular da Universidade de Uberaba, na graduação e na pósgraduação (Programa de Pós-Graduação em Educação - Mestrado e Doutorado), integrando a Linha de Pesquisa "Desenvolvimento Profissional, Trabalho Docente e Processo de Ensino-Aprendizagem". Vice-coordenadora do Programa de Pós-Graduação em Educação no período de 2008 a 2017. Vice-líder dos Grupos de Pesquisa "Desenvolvimento profissional e trabalho docente na contemporaneidade Uniube" e "GEPIDE/ Grupo de Estudos e Pesquisas em Instrução, Desenvolvimento e Educação Uniube" e membro do Grupo de Estudos e Pesquisas sobre Representações Sociais e Práticas Educativas- GEPRESPE. Editora da Revista Profissão Docente.

E-mail: marilene.resende@uniube.br

ORCID: https://orcid.org/0000-0002-6740-1787

Vania Maria Oliveira Vieira possui graduação em Psicologia, Formação de Psicólogos e Licenciatura pela Universidade de Uberaba (1983), graduação em Pedagogia Licenciatura Plena pela Faculdade de Filosofia, Ciências e Letras de Ituverava (1987), mestrado em Educação, Formação de Educadores pela Universidade de Uberaba (2003) e doutorado em Psicologia da Educação pela Pontifícia Universidade Católica de São Paulo (2006). Foi coordenadora do Programa de Pós-Graduação em Educação da Universidade de Uberaba de 2008 a 2017. Atualmente é docente no curso Psicologia e no PPGE/UNIUBE. Atuou como Psicóloga Escolar na Rede de Ensino da Prefeitura Municipal de Uberaba de 1984 a 2014. É pesquisadora associada do Centro Internacional de Estudos em Representações Sociais e Subjetividade/Educação - CIERS-Ed. É coordenadora da RIDEP - Rede de Pesquisa Internacional sobre Desenvolvimento Profissional de Professores. Membro do PIBIC/UNIUBE - Programa Institucional de Bolsas de Iniciação Científica da Universidade de Uberaba. Foi coordenadora do Subprojeto do PIBID Formação de professores: trabalhando a diversidade na escola de 2014 a 2016. Membro do corpo editorial do Periódico: Revista Profissão Docente (Online). É líder do GEPRESPE - Grupo de Estudos e Pesquisas sobre Representações Sociais e Práticas Educativas, vinculado ao Programa de Pós-Graduação em Educação e da Linha de Pesquisa Desenvolvimento Profissional, Trabalho Docente e Processo EnsinoAprendizagem. Líder do Grupo de Pesquisa GDEPRES - Desenvolvimento Profissional Docente e Representações, certificado pelo CNPq em 2016.

E-mail: vaninhaarquivos@gmail.com

ORCID: https://orcid.org/0000-0001-9839-0235 